\title{
Histrelin Regimen
}

National Cancer Institute

\section{Source}

National Cancer Institute. Histrelin Regimen. NCI Thesaurus. Code C160049.

A hormone therapy regimen consisting of histrelin that may be used in the treatment of prostate cancer. 